\title{
A habitação de interesse social no Brasil e sua expressão em Manaus
}

\section{The social interest housing in Brazil and its expression in Manaus}

Elane de Azevedo Pires - Mestre em Psicologia pela Universidade Federal do Amazonas (UFAM). Especialização em Politica Social /Sistema Único de Assistência Social (UNINTER). E-mail :elane_pires@hotmail.com

Marcelo Gustavo Aguilar Calegare - Doutor em Psicologia Social pela Universidade de São Paulo (USP). Professor da Faculdade de Psicologia da Universidade Federal do Amazonas (UFAM). E-mail: mgacalegare@ufam.edu.br

\section{Resumo}

Este artigo aborda de maneira crítica as políticas públicas de habitação de interesse social no Brasil, dando foco ao caso de Manaus. Iniciamos com um breve histórico a respeito das políticas habitacionais brasileiras, revelando que a habitação no país pode ser considerada uma questão social, devido aos indicadores de déficit habitacional, o número expressivo de moradias precárias e programas de habitação de interesse social que não correspondem às expectativas dos beneficiários. Apresentando durante a discussão dados do Amazonas e Manaus, problematizamos a desigualdades no espaço urbano brasileiro, para o qual os poderes públicos têm realizado intervenções insuficientes em anos pretéritos e presentes.

\begin{abstract}
This article critically addresses public housing policies of social interest in Brazil, focusing on the case of Manaus. We begin with a brief history of Brazilian housing policies, revealing that housing in Brazil can be considered a social issue, due to the indicators of housing deficit, the expressive number of precarious housing and the programs of social interest housing that do not meet expectations of the beneficiaries. Presenting during the discussion data from Amazonas and Manaus, we problematize the inequalities in the Brazilian urban space, for which the public authorities have performed insufficient interventions in past and present years.
\end{abstract}

\section{Palavras-chave}

Habitação de Interesse Social. Moradia. Questão Social. Política Pública.

\section{Keywords}

Social Interest Housing. Housing. Social Question. Public Politic. 


\section{INTRODUÇÃO}

A falta de moradia para uma parcela da população em situação de pobreza é um problema presente em todos os países do mundo, desde os menos desenvolvidos às maiores potências mundiais. No Brasil, a questão da ausência de habitação com condições dignas e necessárias para as famílias mais pobres pode ser caracterizada por uma trajetória que perpassa as mais diversas discussões e medidas. As ações dos sucessivos governos buscaram uma saída que atenuasse os impactos gerados pelo crescimento populacional e desenvolvimento industrial, fatos que agravaram as desigualdades sociais e que deram origem ao dilema da questão social habitacional no país (SILVA, 1989).

Essa configuração do problema habitacional também se expressa no Amazonas, especialmente na cidade de Manaus, uma vez que não seguiu uma lógica diferente de outras cidades. O impacto do desenvolvimento industrial dos anos 1960 em diante causou problemas diversos no estado, como o êxodo rural e a explosão demográfica da capital (RANCIARO, 2004). A ausência de uma ação preventiva do poder público referente à ocupação territorial possibilitou que milhares de familiais ocupassem espaços inadequados para moradia, como encostas e margens de igarapés. As localidades que ao longo dos anos foram consolidadas por ocupações em Manaus dispõem de serviços públicos insuficientes, tornando a cidade com um dos maiores e piores déficits relativos do país (FUNDAÇÃO JOÃO PINHEIRO, 2013; OLIVEIRA: COSTA, 2007).

O agravamento da situação habitacional no país teve reflexo direto na insatisfação da população com a atuação do poder público, circunstância que levou o Estado a intervir na produção habitacional, que por longos anos ficou sob responsabilidade da iniciativa privada. Historicamente, a atuação estatal no âmbito da habitação para a população mais pobre teve início a partir de 1910, com o lançamento de programas que se propunham atenuar o déficit habitacional brasileiro, por meio do financiamento de moradias (FERNANDES; OLIVEIRA, 2010). Este tipo de iniciativa se repetiu por longos anos até a presente década, delineando-se um perfil socioeconômico para as famílias necessitadas de moradia e constituindo um desafio urbano para a habitação de interesse social.

A habitação de interesse social (HIS) é um tipo de moradia produzida para atender a necessidade de moradia de um grupo de famílias que se inserem no perfil socioeconômico de extrema pobreza a baixa renda, isto é, que possuem rendimentos de zero a três salários mínimos. Portanto, não possuem condições financeiras para obter a casa própria no âmbito do mercado capitalista, no qual os imóveis considerados adequados para moradia têm muitas vezes valores 
exorbitantes. Sendo assim, as HIS são normalmente subsidiadas pelo poder público e que também seleciona as famílias que serão beneficiárias.

Para fundamentar a discussão a respeito da HIS no Brasil e como esta se apresenta no Amazonas e, mais especificamente, em Manaus, neste artigo temos por objetivo apresentar uma revisão crítica da literatura sobre o tema, demonstrando que a habitação se configura como uma questão social devido ao número crescente de famílias que residem em locais sem condições dignas de moradia. Os vários autores que desenvolveram estudos sobre habitação contribuíram para revelar que o Brasil é um país com graves problemas na área habitacional (AZEVEDO, 2007; FUNDAÇÃO JOÃO PINHEIRO 2013; MARICATO, 1996; OLIVEIRA, COSTA, 2007) - o que se reflete também no estado do Amazonas e sua capital. Nesse sentido, apresentaremos um breve histórico das políticas habitacionais no âmbito da HIS no período de 1910 a 2014, mostrando também como estas são executadas em Manaus. Em seguida, faremos uma discussão da habitação enquanto questão social no Brasil, trazendo dados de todo país - e com destaque para Manaus - utilizados pelo governo federal a partir dos estudos da Fundação João Pinheiro, uma vez que a capital amazonense tem enfrentado graves problemas relacionados à habitação.

\section{A HABITAÇÃO DE INTERESSE SOCIAL NO CONTEXTO BRASILEIRO E EM MANAUS}

A HIS surgiu no Brasil por meio da produção de moradias operárias no governo de Marechal Hermes (1910-1914). Tais moradias consistiam em vilas proletárias destinadas aos operários residentes no bairro Marechal Hermes, no Rio de Janeiro. Como argumentam Fernandes e Oliveira (2010), a construção das vilas pode ser considerada como uma das primeiras iniciativas para o enfrentamento da questão social na área da habitação por parte do Estado no país, sendo precursoras da intervenção habitacional no período Vargas. As vilas operárias localizavam-se no centro das cidades próximas às indústrias. No entanto, esse tipo de moradia era oferecido aos trabalhadores mais qualificados das indústrias. Devido à inexistência de qualquer iniciativa que pudesse prover habitação para grande parte dos trabalhadores pobres, somado à falta de condições econômicas para pagar uma moradia digna, muitas famílias foram obrigadas a morar nos cortiços da cidade. Pertencentes à iniciativa privada e localizados no centro, os cortiços eram caracterizados por ser uma habitação coletiva, com edificações velhas e banheiro de uso coletivo. 
As vilas de Hermes foram planejadas para abrigar cerca de cinco mil pessoas, suas obras foram iniciadas no governo do Marechal Hermes, mas sua conclusão só ocorreu no governo de Getúlio Vargas, em 1941. Vargas iniciou a sua intervenção nas obras das vilas por meio do Instituto de Previdência dos Funcionários Públicos da União (IPFPU). Fernandes e Oliveira (2010) afirmam que apesar de Vargas ter dado continuidade às obras das vilas, ele reconheceu a intervenção da República Velha para amenizar a questão social habitacional. Isso contribui para que Marechal Hermes não tivesse sua atuação reconhecida no âmbito da habitação social no Brasil.

Para Bonduki (1994), outro marco a ser considerado na trajetória da HIS consiste na Lei do Inquilinato (1921-1927), que surgiu com resultado da intervenção do Estado na produção de moradias e proteção ao inquilinato, visando conquistar as massas populares que enfrentavam problemas na área habitacional. Dessa forma, tal lei preconizava o congelamento monetário dos aluguéis em virtude dos altos valores que contribuíam para agravar a crise por falta de moradia que vigorava naquele período. Assim, o Estado

assume a peculiaridade da habitação como uma mercadoria especial, onde o interesse social ultrapassa os mecanismos de mercado. Reforça, portanto, independentemente da intenção de seus idealizadores, a visão da habitação social no Brasil (BONDUKI, 1994, p. 719).

Com o objetivo de reforçar sua presença na intervenção habitacional, o Estado criou em 1933 os Institutos de Aposentadorias e Pensões (IAP), que buscavam viabilizar uma política habitacional direcionada para a classe trabalhadora (CABRAL, 2005), além de financiar, paralelamente, a habitação social e a construção civil. Os IAP construíram moradias em benefício de seus associados e tiveram uma importante intervenção reconhecida, pois construíam moradias com boa localização (BONDUKI, 1994). Apesar disso, os IAP encerraram suas atividades, pois não obtiveram retorno financeiro de seus investimentos.

De acordo com Motta (2010), a principal marca da política habitacional no período de Vargas foi a criação da Fundação Casa Popular (FCP) em 1946, sendo a primeira política nacional de habitação de fato. A FCP foi o primeiro órgão federal brasileiro na área de moradia que se propôs a centralizar a política de habitação (CABRAL, 2005). Entretanto, a FCP não dispunha dos recursos necessários para seu desempenho, além de não terem produzido moradias suficientes para atender a demanda durante seus vinte anos de existência e, assim, foi extinta em 1964 (BRASIL, 2004). 
Com o fim da FCP, em 1964, foi criado o Banco Nacional de Habitação $(\mathrm{BNH})$ no mesmo ano. A iniciativa foi considerada a primeira intervenção significativa do Estado na questão habitacional. Isso contribuiu para que o governo militar alcançasse o apoio das massas populares e estruturasse uma política voltada para o setor da construção civil habitacional (BONDUKI, 1994).

$\mathrm{O} \mathrm{BNH}$ visava propiciar às classes populares a oportunidade de aquisição da casa própria. Abiko (1995 citado por LARCHER, 2005, p. 10) relembra que "o interesse social como terminologia na habitação no Brasil já era utilizado nos programas para faixas de menor renda do extinto Banco Nacional da Habitação (BNH)". O procedimento adotado para a realização de tal feito consistia em oferecer financiamentos para os agentes que executavam programas habitacionais, os quais transferiam o dinheiro para as empresas de construção. Dessa forma, o $\mathrm{BNH}$ deveria tornar viável a aquisição de moradias para os brasileiros, mas seu funcionamento não favorecia a compra dessas casas pelas classes desfavorecidas (VALLADARES, 1981). A alternativa encontrada pelas classes de pobres frente à ineficiência do $\mathrm{BNH}$ consistia na compra de loteamentos, que eram revendidos a preços acessíveis, de modo que os novos proprietários construíam sua própria casa. A autoconstrução resultou em inúmeras residências em condições precárias, pois as famílias não possuíam renda suficiente para investir em uma moradia com infraestrutura adequada e boa localização, em virtude dos preços de terrenos próximo ao centro serem muito caros.

Foram desenvolvidos muitos debates e propostas a fim de encontrar medidas de descentralização do $\mathrm{BNH}$, mudanças no sistema de financiamento, operação e receita dos sistemas, mas nenhuma dessas alternativas foi satisfatória e o banco foi extinto em 1986. Nesse sentido, suas atribuições foram transferidas para a Caixa Econômica Federal (AZEVEDO, 2007).

Com a Constituição de 1988, passou a ser competência dos estados e municípios "a gestão dos programas sociais, e dentre eles o de habitação, seja por iniciativa própria, seja por adesão a algum programa proposto por outro nível de governo, seja por imposição Constitucional” (BRASIL, 2004, p. 10). Bonduki et al. (2003 citados por LARCHER, 2005) afirmam que a Constituição Federal de 1988 passou a atribuir ao solo urbano uma função social. Dessa forma, agregou-se a isso "o conceito de Interesse Social, que é constitucionalmente incorporado às políticas habitacionais para os setores de população de baixa renda" (LARCHER, 2005 p.10).

Durante os anos 1990, houve poucos investimentos significativos no âmbito habitacional (MOTTA, 2010). A política habitacional foi caracterizada pela alocação das unidades construídas pelos programas populares e alternativos, 
baseados na autoconstrução, além de que a construção dessas unidades continuou privilegiando os setores populares de renda elevada (AZEVEDO, 2007). Em maio de 1990, foi lançado o Plano de Ação Imediata para a Habitação, o mais importante programa habitacional criado pelo governo Collor, que tinha como objetivo as famílias com renda de zero a cinco salários mínimos. Tal programa possuía como vertentes: "programa de moradias populares (unidades acabadas), programa de lotes urbanizados (com ou sem cesta básica de materiais) e programa de ação municipal para habitação popular (unidades acabadas e lotes urbanizados)" (AZEVEDO, 2007, p. 20).

Com vistas a dar continuidade às obras iniciadas no governo anterior, durante a gestão de Itamar (1992-1994) foram criados os Programas Habitar Brasil e Morar Município, os quais objetivavam o financiamento de moradias para a população de baixa renda (MOT'TA, 2010). Enquanto o Programa Habitar Brasil era voltado para os municípios com população superior a 50 mil habitantes, o Morar Brasil destinava-se aos municípios com menor porte, sendo que ambos possuíam as mesmas características e estavam direcionados às famílias de baixa renda e que viviam em áreas de risco (AZEVEDO, 2007).

O governo FHC (1995-2002), por sua vez, registrou sua intervenção na HIS por meio de alguns programas habitacionais: o "Programa de Conclusão de Empreendimentos Habitacionais", que buscava viabilizar a comercialização de conjuntos habitacionais; e o "Programas de Crédito Direto ao Cidadão", denominados Cred-Mac e Cred-Casa. Estes eram voltados para famílias com rendimentos de até oito salários mínimos, com fins de possibilitar a oferta de crédito para facilitar a aquisição de materiais de construção. Programas que merecem destaque também no governo de FHC são "Pró-Moradia" e o "Programa Habitar Brasil", os quais tinham como finalidade "a urbanização de áreas degradadas para fins habitacionais, a regularização fundiária e a produção de lotes urbanizados" (AZEVEDO, 2007, p. 24). Entre os programas que migraram do governo FHC para o governo Lula (2003-2010) está a Carta de Crédito, individual e associativa, além do programa Pró-Moradia, com foco na urbanização de áreas precárias.

O governo Lula estabeleceu um plano de trabalho focado para a área social, em que uma de suas principais metas era reduzir o déficit habitacional. Assim, criou-se o Ministério das Cidades, responsável por tratar de questões voltadas para o desenvolvimento urbano do país. E vinculado ao mesmo, a Secretaria Nacional de Habitação, que gerencia e faz cumprir as ações previstas na política habitacional. 
A Política Nacional de Habitação, instituída em 1994, foi considerada um instrumento significativo no avanço em termos participativos, institucionais e legais para a habitação. Assim, em 2003, é instituído o conselho das cidades e o Sistema Nacional de Habitação ( $\mathrm{SNH}$ ), que reúne os esforços dos três níveis de governo, do mercado, das cooperativas e associações populares para promoção de moradia digna.

Vale destacar que as principais providências executadas foram a implementação de ações que favorecessem a construção civil, com a diminuição dos impostos sobre os materiais de construção, direcionamento dos recursos do Sistema Brasileiro de Poupança e Empréstimo (SBPE) e do Fundo de Garantia do Trabalhador (FGTS) para a Caixa Econômica Federal, bem como aumento dos subsídios e redução da taxa de juros (BRASIL, 2010). Desse modo, o SNH passou a se articular com eixos voltados para a política de desenvolvimento urbano no país, que prevê não só a habitação como também a mobilidade urbana, a acessibilidade e o saneamento básico.

O SNH está subdividido em dois sistemas: o Sistema Nacional de Habitação de Interesse Social (SNHIS) e o Sistema Nacional de Mercado (SNM). Esses dois sistemas operam com fontes de recursos, formas e condições de financiamento diferentes. O SNHIS é voltado para atender à população de baixa renda de zero a três salários mínimos, com recursos subsidiados pelo governo para as famílias que, prioritariamente, moram em “assentamentos precários" - termo que definiremos mais adiante. E o SNM para atender a classe média com renda acima de três salários mínimos com recursos emprestados para os usuários. Para acessar os recursos do fundo e aderir ao SNHIS, os estados, o Distrito Federal e os municípios deverão tomar medidas de âmbito institucional, comprometendo-se a constituir um Fundo Local de Habitação de Interesse Social, criar um Conselho Gestor do Fundo Local e elaborar um Plano Local de habitação de interesse social. Assim, os dois estabelecem processos para a provisão de moradias em todos os segmentos sociais (BRASSIL, 2010).

A aprovação do SNHIS é considerada também uma conquista dos movimentos populares, já que seu projeto de lei foi resultado de uma mobilização nacional dos movimentos de luta por moradia e de diversas entidades. Esse projeto de lei foi apresentado no parlamento, em 19 de novembro de 1991, por organizações e movimentos populares urbanos filiados ao Fórum Nacional de Reforma Urbana, tendo sido assinado por mais de um milhão de pessoas.

Um importante instrumento criado em 2001 foi o Estatuto das Cidades, que proporcionou nova fundamentação jurídica para a efetivação do "direito à cidade", o que significa ter acesso a aparelhos comunitários (escolas, posto de 
saúde lazer, transporte etc.) - mas isto não quer dizer que de fato funcione como preconiza a lei. O Estatuto engloba a função social da propriedade, o direito à moradia e a participação popular, dispõe sobre instrumentos capazes de permitir a efetividade da função social da propriedade e a segurança da posse.

O Estatuto das Cidades pretende definir como regular a propriedade urbana, de modo que os processos que a envolvem não se constituam empecilhos ao direito à moradia para a maior parte da população. No entanto, “aplicar o Estatuto da Cidade em tal contexto, culturalmente excludente, tradicionalmente conservador, não é tarefa simples especialmente porque nessas sociedades chamadas de emergentes (...) ou periféricas, o poder político e social vem associado à propriedade patrimonial" (MARICATO, 2010, p.06).

Ainda no governo Lula foi anunciado o Plano de Aceleração do Crescimento (PAC), em que no eixo da infraestrutura urbana e social foi incluído o Programa Minha Casa Minha Vida (PMCMV), inspirado na experiência chilena de habitação. O SNH, o Estatuto das Cidades e o PMCMV foram importantes ações mantidos no governo Dilma (2010-2016). O PMCMV se expandiu e era o programa mais executado em nível nacional, tendo como principal objetivo contemplar as famílias de baixa renda com moradia digna, podendo ser organizadas por meio dos municípios, construtoras ou entidades habilitadas (BRASIL, 2010). E quanto ao governo Temer, também se manteve esse programa e se implementou o "Cartão Reforma", que se trata de um auxílio às famílias para reformarem suas casas.

O PMCMV apresenta em sua estrutura a modalidade Entidades, uma novidade não constatada em programas passados. Essa inovação possibilitou que os movimentos sociais fossem agentes efetivos na produção de moradia no país. Nesta modalidade, qualquer associação ou cooperativa que fosse legalmente regularizada poderia atuar como organizadora das famílias de baixa renda. O processo acontece da seguinte forma: a entidade apresenta os documentos de qualificação técnica e institucional para a Caixa Econômica Federal no período estabelecido em portaria. A Caixa analisa a documentação e envia o relatório para o Ministério das Cidades. A homologação do resultado é publicada no Diário Oficial da União. Se a entidade for aprovada, ela poderá atuar na gestão para construção de até 1.000 moradias.

O Fundo de Desenvolvimento Social subsidia até 95\% do valor da casa e a Caixa acompanha e fiscaliza todas as fases da obra. Para participar do PMCMVEntidades, as famílias devem atender aos seguintes critérios prioritários:

1. Ser família de baixa renda até três salários mínimos;

2. Estar inscrita no cadastro único do governo federal; 
3. Residir em áreas de risco ou insalubres;

4. Famílias com mulheres responsáveis pela unidade familiar;

5. Famílias que tenham em sua composição pessoas com deficiência e idosas.

Feita essa breve recapitulação de como foram delineadas as políticas públicas voltadas à resolução da questão da habitação no país, é importante entendermos como tal questão se tornou um problema também no estado do Amazonas e, especialmente, na sua capital, e quais as políticas praticadas nessa cidade. Em linhas gerais, em Manaus a apropriação do espaço e a consolidação de moradias não obedeceu uma lógica diferente de outros contextos brasileiros. A urbanização dessa cidade e, consequentemente, sua ocupação acelerada, iniciou a partir da consolidação da Zona Franca de Manaus (ZFM) nos anos 1960, como explicaremos adiante.

Após o declínio da economia da borracha na segunda década do século $\mathrm{XX}$, a população do interior do estado do Amazonas dedicava-se ao extrativismo vegetal, à agricultura e à pecuária de pequeno porte direcionada para o abastecimento da capital, além das atividades de subsistência. No entanto, esse modelo de economia era considerado fraco e insuficiente e não poderia garantir o desenvolvimento social e econômico da região. Segundo Ianni (1986), a partir de 1966 se iniciou uma nova fase de desenvolvimento extensivo do capitalismo na Amazônia, resultado da expansão acelerada das relações de produção, forças produtivas no extrativismo, agricultura e pecuária. Foi nesse contexto de inclusão da Amazônia no modelo econômico desenvolvimentista do governo militar que foi criada a ZFM, por meio do Decreto-Lei n⿳ำ 288, de 28 de fevereiro de 1967. Seu objetivo era atrair interesses econômicos e financeiros com a oferta de incentivos fiscais especiais e de uma área livre para o comércio de importação e exportação de mercadorias. Essas medidas possibilitaram o desenvolvimento econômico da Amazônia ocidental, resultando no aumento da oferta de empregos, incentivo ao turismo interno e o desenvolvimento industrial agropecuário. Como a ZFM necessitava absorver mão-de-obra, muitas pessoas migraram para a capital amazonense em busca de empregos.

De acordo com Ranciaro (2004), o advento da ZFM deu notório destaque à cidade. No entanto, esta nova estruturação, somada ao crescimento do comércio de produtos importados, gerou distorções sem precedentes, dentre os quais se destacam a concentração econômica na capital amazonense e o êxodo rural acelerado. Isso inegavelmente provocou o desenvolvimento das desigualdades sociais, visto que as oportunidades de emprego não acompanharam a explosão demográfica, gerando certos problemas sociais como o crescimento populacional 
acelerado e desordenado.

Oliveira e Costa (2007) afirmam que a consolidação de moradias em Manaus se iniciou com a expansão dos conjuntos residenciais, que foram construídos por meio da iniciativa privada com subsídios oferecidos pelo Estado, via incentivos financeiros do BNH. Os conjuntos foram formados nos bairros do Japiim, Flores, Petro e Cidade Nova. As casas eram padrão e foram construídas horizontalmente, no entanto atualmente dificilmente encontram-se as casas em sua estrutura original.

Com o objetivo de amenizar o problema habitacional da cidade, foram implantados alguns programas de HIS, com a iniciativa dos poderes públicos locais, com incentivos financeiros do Governo Federal e bancos internacionais. Os programas executados mais conhecidos em Manaus são os seguintes:

- PROSAMIM - Programa Social e Ambiental dos Igarapés de Manaus. A prática do programa se caracteriza por recuperar áreas de igarapé mais próximas do centro da cidade onde residem determinado número de famílias. As mesmas são remanejadas das áreas até que sejam feitos serviços de drenagem do solo e onde são construídas novas habitações de forma verticalizada;

- Residenciais "Viver Melhor". São casas e apartamentos que foram construídos para atender às necessidades habitacionais de famílias que não possuem moradia e seguem os parâmetros de exigência do PMCMV do Governo Federal.

Há também outras iniciativas conhecidas na área da habitação como: "os conjuntos cidadãos", PMCMV-entidades e o programa "Cartão Reforma", iniciativa mais recente do governo federal criada pelo governo Temer, gerenciada pela secretaria de habitação do município. Para participar deste programa as famílias devem estar em situação de pobreza ou baixa renda e ter o título definitivo do terreno. Nesse sentido, a família recebe gratuitamente o valor de até $\mathrm{R} \$ 9.000,00$ para realizar reforma de cômodos, conserto de telhado, hidráulica, elétrica e esgoto.

\section{A QUESTÃO SOCIAL DA HABITAÇÃO NO BRASIL E EM MANAUS}

Segundo Maricato (2010), em países desenvolvidos como o Canadá, $30 \%$ da população necessitam de subsídios para resolver seus problemas de moradia, enquanto no Brasil essa estatística chega até $70 \%$. Em nosso país, mais de um milhão de famílias residem em assentamentos precários sem as mínimas condições de moradia. 
A questão da habitação pode ser considerada mais um entre os muitos problemas sociais urbanos do Brasil, o que reflete um século de políticas que de fato não privilegia a população mais pobre. Por muitos anos o Estado relegou a questão social da habitação atuando de forma paliativa, excludente e autoritária, visando a lucratividade e na maioria dos casos movidas por interesses secundários. Dito de forma mais direta, visando obter lucros para a máquina pública, ou por vezes com mero intuito de promoção política partidária (SILVA, 1989).

Apesar de toda luta dos movimentos populares, da legislação e dos esforços do governo federal para prover moradia digna às famílias pobres, a execução dos projetos de HIS ainda esbarra em um antigo problema do país: devido à situação agrária, ao metro quadrado dos terrenos nos centros das cidades terem valores exorbitantes e pela especulação imobiliária, grande parte das casas dos programas sociais são construídas em terrenos distantes. Isso acontece porque o recurso para execução dos programas é insuficiente para pagar um terreno mais próximo aos centros urbanos, causando a segregação espacial.

Assim sendo, as famílias que têm esperança de obter uma moradia digna são reassentadas em terras que ficam no entorno da cidade. Esses locais são caracterizados por serem distantes, por não terem aparelhos comunitários, entre outros serviços, que possam atender à necessidade dos moradores. Por isso, algumas famílias abandonam os locais da nova moradia e voltam para o seu lugar de origem, onde têm escola, padaria, posto de saúde etc. com mais fácil acesso. Para exemplificar essa realidade, basta observarmos onde estão sendo construídos os conjuntos do programa "Viver Melhor", executado pelo Governo do Estado em Manaus. O último empreendimento desse programa foi construído no bairro de Santa Etelvina, localizado próximo aos limites da cidade, muito distante do centro e de outras zonas comerciais.

De acordo com Maricato (2010), parte das grandes cidades brasileiras têm sua população morando em locais sem qualquer regularização urbanística. No sistema capitalista, o acesso à moradia obedece a meios altamente diferenciados, vinculados à lógica da produção, em que a apropriação do espaço na cidade vai sendo configurado de acordo com os interesses de classes e criando desigualdades na vida social. O salário da maioria dos trabalhadores não tem sido, em épocas passadas e atuais, suficiente para que se possa prover uma moradia digna para suas famílias, obrigando-os a criar estratégias de sobrevivência e de provisão, em geral precárias e desumanas. $\mathrm{O}$ alto custo dos imóveis em áreas centrais, com eficiente estrutura urbana, exclui a possibilidade de cidadãos pobres viverem nestas áreas. Desse modo, são obrigados a morar em locais distantes com pouca ou quase nenhuma infraestrutura básica. 
A ausência de opções habitacionais no Brasil, criada pelo intenso processo de urbanização, baixa intervenção do poder estatal, baixa renda das famílias, especulação de terra urbanizada e insuficiência das políticas de habitação, levaram uma grande parte da população brasileira a viver em assentamentos precários e informais. Assim, as décadas de 1980 e 1990 foram marcadas pela expansão dos assentamentos precários, agravados pela crise econômica e pelo empobrecimento da população (BRASIL, 2010).

O termo "assentamentos precários" foi incorporado pela Política Nacional de Habitação, com o objetivo de definir em âmbito nacional um conjunto de moradias urbanas consideradas inadequadas para habitação que incluem cortiços, loteamentos irregulares de periferia, favelas, assim como os conjuntos habitacionais que se acham degradados. Segundo o Ministério das Cidades (BRASIL, 2010), os assentamentos precários são porções do território urbano com dimensões e tipos variados, que geralmente seguem as seguintes características:

1. São áreas predominantemente residenciais, habitadas geralmente por famílias de baixa renda;

2. As casas são caracterizadas por possuírem inúmeras carências e inadequações, como: irregularidade fundiária, ausência de infraestrutura e saneamento;

3. Estão em locais com enormes distâncias dos centros urbanos;

4. Em sua grande parte não possuem um serviço de transporte que consiga atender a grande demanda populacional;

5. Inexistência ou deficiência de serviços públicos como: saúde, educação, lazer etc.;

6. Os terrenos podem apresentar perigos de alagamento, deslizamentos e outros tipos de risco;

7. Adensamento excessivo dos assentamentos e das edificações, insalubridade e deficiências construtivas da unidade habitacional;

8. Estão localizados em território de extrema vulnerabilidade, com predomínio de situações de violência e tráfico;

Para Maricato (2010), além da ilegalidade e dos altos índices de violência, estão presentes nesses bairros mais vulneráveis: alta taxa de mulheres chefes de famílias, maior taxa de desemprego, baixa escolaridade, renda abaixo da renda média urbana, alta taxa de mortalidade infantil, ocorrência frequente de doenças por epidemia etc. As autoridades públicas e até mesmo a polícia têm dificuldade de circular livremente por essas áreas. Além disso, o autor ressalta que "num mesmo momento histórico, estão presentes os modos de vida pré-moderno (a 
produção doméstica da moradia, a proximidade dos dejetos) convivendo com o modo de vida pós-moderno baseado na comunicação revolucionada” (p. 38).

Os assentamentos precários são classificados em "consolidados", "consolidáveis" e "não consolidáveis", conforme as definições do Ministério das Cidades (BRASIL, 2010) a seguir:

Consolidados: são assentamentos que já estão integrados urbanisticamente e dotados de infraestrutura básica, porém, não estão regularizados e seus moradores apresentam demandas específicas por programas de pós-ocupação, sociais e equipamentos e serviços públicos.

Consolidáveis: aquele que apresenta condições favoráveis de recuperação urbanística e ambiental e de reordenamento urbano, abertura ou readequação de sistema viário, implantação de infraestrutura básica, regularização urbanística do parcelamento do solo, com ou sem necessidade de remoção de parte das famílias moradoras. A realocação (remoção) pode ser necessária para eliminar situações de risco, promover o desadensamento, para executar intervenções urbanas ou, ainda, em função de restrições legais à ocupação.

Não consolidáveis: aqueles que não apresentam condições de recuperação urbanística e ambiental e de reordenamento urbano. Trata-se de núcleos comprometidos por situações de risco e insalubridade não solucionáveis, como, por exemplo, os que se localizam sob aterro sanitário, oleoduto, viário estrutural da cidade, áreas de risco, de preservação ambiental. Os núcleos "não consolidáveis" são objeto de intervenção do tipo "remoção" e reassentamento em novas áreas.

Conforme a descrição do Ministério das Cidades (BRASIL, 2010), é possível perceber que o problema da habitação não é só a falta da casa, mas possui várias dimensões relacionadas à falta de infraestrutura, saneamento básico, mobilidade urbana e regularização fundiária. Na ausência de uma política fundiária que favoreça os mais pobres, a ocupação de terrenos áreas de risco ou ambientalmente frágeis é a opção que muitas vezes sobra para a população que não consegue acesso aos programas públicos habitacionais.

A Fundação João Pinheiro (2013) demonstra indicadores quantitativos que revelam a realidade dos assentamentos precários no Brasil. Essas estatísticas são utilizadas oficialmente pelo Governo Federal para divulgar as necessidades habitacionais mais recentes no país. O déficit habitacional no Brasil supera 6,490 milhões de unidades e inclui moradias que são classificadas em quatro categorias, conforme as descrições a seguir: 
Domicílios precários: um conjunto de moradias que por sua situação de precariedade não tem condições de serem habitadas. Podem ser representados por aqueles domicílios que não são de alvenaria. Os materiais (taipa não revestida, madeira aproveitada, palha) utilizados possuem vida útil e oferecem risco à saúde ou são muito antigos. Também são representados por aqueles domicílios improvisados utilizados como moradia, mas que não servem para este fim, como, por exemplo, carcaça de carros abandonados, viadutos, imóveis comerciais, barracas, cavernas e outros.

Coabitação familiar: representado por famílias conviventes que têm a intenção de ter o seu próprio domicílio. São famílias secundarias que moram com uma família principal na mesma unidade habitacional. Geralmente a família principal cede ou aluga um cômodo da casa para famílias conviventes ou terceiros.

Ônus excessivo com aluguel: representado por famílias de baixa renda que não reúnem capacidade econômica suficiente para pagar aluguel. Este componente inclui as famílias com até três salários mínimos e que utilizam até $30 \%$ da renda para pagar o imóvel.

Adensamento excessivo de domicílios alugados: caracterizado por número de pessoas que utilizam o mesmo cômodo como dormitório; neste caso, foi considerado um único dormitório para o número acima de três moradores permanentes.

Portanto, o déficit habitacional é formado pelos domicílios que precisam ser repostos por serem caracterizados como precários e pela falta de domicílios que precisam ser construídos, considerando o número de famílias que não têm casa própria. Tal déficit é calculado somando os quatro componentes: domicílios precários, coabitação familiar, ônus excessivo com aluguel urbano e adensamento excessivo de domicílios alugados. Os componentes são calculados de forma sequencial e, para contar como déficit, basta que o domicílio atenda no mínimo um único critério. $\mathrm{O}$ cálculo do déficit relativo é feito dividindo o número de déficit da unidade de análise pela soma de domicílios particulares permanentes e improvisados existentes. Tal indicador "é extremamente relevante, pois é capaz de revelar as necessidades habitacionais neutralizando o efeito tamanho do município no indicador final" (FUNDAÇÃO JOÃO PINHEIRO, 2013, p. 24).

$\mathrm{Na}$ Tabela 1 são apresentados dados da estimativa do déficit habitacional levantados pela Fundação João Pinheiro (2013), com base no censo demográfico publicado pelo IBGE (2010), que apresenta as necessidades mais recentes na área da habitação no Brasil. 
Tabela 1 - Déficit habitacional absoluto e relativo

\begin{tabular}{l|r|r|r|r|r|r}
\hline \multirow{2}{*}{ Região } & \multicolumn{3}{|c|}{ Absoluto $\left(\mathbf{n}^{\circ}\right)$} & \multicolumn{3}{c}{ Relativo (\%) } \\
\cline { 2 - 7 } & Urbano & \multicolumn{1}{|c|}{ Rural } & \multicolumn{1}{c|}{ Total } & Urbano & Rural & \multicolumn{1}{c}{ Total } \\
\hline Norte & 585.725 & 237.17 & 823.442 & 19,4 & 24,7 & 20,6 \\
\hline Nordeste & 1.532 .184 & 579.333 & 2.111 .517 & 13,7 & 15,6 & 14,1 \\
\hline Sudeste & 2.576 .502 & 97.925 & 2.674 .428 & 10,9 & 5,9 & 10,6 \\
\hline Sul & 685.111 & 85.639 & 770.749 & 9,0 & 6,7 & 8,7 \\
\hline Centro-Oeste & 506.006 & 54.599 & 560.555 & 13,1 & 11,5 & 12,9 \\
\hline Brasil & 5.885 .528 & 1.055 .163 & 6.490 .691 & 11,9 & 13,0 & 12,1 \\
\hline
\end{tabular}

Fonte: Fundação João Pinheiro (2013)

Os dados apontam que há um déficit habitacional de 6,490 milhões de unidades no Brasil, o que corresponde a 12,1\% de residências. Os dados da Tabela 1 demonstram que a região Sudeste concentra o maior déficit habitacional, com 2,674 milhões de unidades, o que representa $41 \%$ do total absoluto. Em seguida vem a região Nordeste, com 1,495 milhões unidades, o que são $33 \%$ do total absoluto. A região Centro-Oeste possui o menor déficit, com apenas 560 mil unidades. Em valores relativos, ou seja, comparando o total de déficit com o número de domicílios particulares permanentes por região, o Norte apresenta os maiores e piores resultados, isto é, $20,6 \%$ dos domićlios da região se enquadram em algum critério de déficit. A região Sul é a que apresenta o menor déficit habitacional relativo do país, com 8,7\% (FUNDAÇÃO JOÃO PINHEIRO, 2013).

Segundo a Fundação João Pinheiro (2013), os assentamentos precários se constituem como um território com tamanhos e tipos variados, caracterizados por inúmeras carências e inadequações. Nesse sentido, pode-se afirmar que esses números não retratam a verdadeira demanda habitacional do Brasil, já que a pesquisa foi feita por unidades habitacionais distinguindo-os por categorias e não por território.

Sendo assim, não foi encontrada uma pesquisa que demonstrasse em números a quantidade de assentamentos precários nas cidades brasileiras. Assim, podemos inferir que há casas contabilizadas em assentamentos precários que foram caracterizadas como dignas para moradia, considerando que há famílias nesses territórios que possuem condições financeiras para construir uma casa com estrutura adequada para habitação. Segundo a Fundação João Pinheiro (2013), casas assentadas em locais sem asfaltamento, saneamento básico, água tratada, energia elétrica regularizada, entre outros, não são adequadas para serem habitadas. Isso nos leva a concluir que todas as casas consolidadas em assentamentos precários deveriam ser calculadas como déficit habitacional, pois 
se fossem incentivadas obras de infraestrutura em um determinado assentamento precário, as famílias teriam que ser remanejadas e novas habitações deveriam ser construídas no mesmo assentamento que fora recuperado. Desse modo, o déficit habitacional parece ser muito maior do que o divulgado nas pesquisas oficiais.

$\mathrm{Na}$ Tabela 2, podemos verificar o déficit habitacional por componente: domićlios precários, coabitação familiar, ônus excessivo com aluguel, adensamento excessivo de domicílios alugados. De acordo com os dados expostos, a coabitação familiar ocupa o maior número do déficit habitacional do país $(39,4 \%$ do déficit total) e o ônus excessivo com aluguel ocupa o segundo lugar nas justificativas pela falta de moradia (30,6\% do déficit). Ambos somados representam $70 \%$ do total do déficit habitacional, o que corresponde a aproximadamente 5,1 milhões de unidades. Vale ressaltar que no ônus excessivo com aluguel estão incluídas somente as famílias consideradas de baixa renda, com ganhos de 0 a 3 salários mínimos, que somam 2.124.409 milhões de famílias pobres. Além de não possuírem meios suficientes para prover o sustento de suas famílias, precisam comprometer uma boa parte de sua renda para pagar a moradia, que quase sempre pelo baixo valor são de péssima qualidade.

Tabela 2 - Déficit habitacional por componente

\begin{tabular}{l|r|r|r|r}
\hline \multicolumn{1}{c|}{ Região } & \multicolumn{1}{c|}{ Precários } & \multicolumn{1}{c|}{ Coabitação } & \multicolumn{1}{c|}{ Ônus } & \multicolumn{1}{c}{ Adensamento } \\
\hline Norte & 303.261 & 352.661 & 121.893 & 45.687 \\
\hline Nordeste & 603.000 & 923.984 & 479.541 & 104.992 \\
\hline Sudeste & 175.238 & 1.165 .196 & 1067.265 & 266.729 \\
\hline Sul & 172.822 & 309.276 & 259.799 & 28.853 \\
\hline Centro-Oeste & 89.114 & 240.255 & 195.906 & 35.279 \\
\hline Brasil & 1.343 .435 & 2.991 .313 & 2.124 .409 & 481.53 \\
\hline
\end{tabular}

Fonte: Fundação João Pinheiro (2013)

Essa realidade pode ser constatada mais intensamente nas regiões Nordeste, Sudeste, Sul e Centro-Oeste, onde o número de domicílios precários é menos expressivo, mas o ônus excessivo com aluguel é alto. Os domicílios precários assumem a terceira posição do déficit habitacional total do país $(19,4 \%)$. Nas regiões Norte e Nordeste, os domicílios precários aparecem com maior percentual que nas demais regiões. Em suma, o adensamento excessivo de domicílios alugados e os domicílios precários são os menos expressivos do déficit, somando cerca de 1,8 milhões de unidades.

Por outro lado, um dado que merece destaque é a quantidade de domicílios vagos nas regiões brasileiras identificados na zona urbana ou rural, conforme 
revelado pela Tabela 3. A maioria desses imóveis se concentram em áreas centrais e, portanto, atendidas por infraestrutura e oferta de serviços urbanos. Conforme se observa, o Brasil tem 6,052 milhões de domicílios vagos. Esse valor se aproxima do déficit de 6,490 milhões de unidades. Essa aproximação dos dados nos leva a refletir se a ocupação desses domicílios vagos solucionaria o problema habitacional do país. No entanto, não foram localizados estudos que comprovem que a ocupação dos domicílios vagos poderia solucionar ou amenizar o problema do déficit habitacional.

Tabela 3 - Domicílios vagos

\begin{tabular}{l|l|l|l}
\hline \multicolumn{1}{c|}{ Região } & \multicolumn{1}{c|}{ Urbano } & \multicolumn{1}{c}{ Rural } & \multicolumn{1}{c}{ Total } \\
\hline Norte & 307.292 & 98.338 & 405.630 \\
\hline Nordeste & 1.216 .995 & 715.976 & 1.932 .971 \\
\hline Sudeste & 2.095 .381 & 352.784 & 2.448 .165 \\
\hline Sul & 654.354 & 157.141 & 811.495 \\
\hline Centro-Oeste & 382.956 & 70.944 & 453.900 \\
\hline Brasil & 4.656 .978 & 1.395 .183 & 6.052 .161 \\
\hline
\end{tabular}

Fonte: Fundação João Pinheiro (2013)

Apesar dos dados revelarem existir muitos domicílios vagos, sabe-se que é comum no Brasil a prática da especulação imobiliária e que, muitas vezes, os poderes públicos preferem assumir uma posição de neutralidade nas discussões sobre tais assuntos, pois esses imóveis, geralmente, pertencem a pessoas com alto poder aquisitivo.

Com relação ao déficit habitacional, o estado do Amazonas apresenta um dos maiores e piores resultados em nível nacional, conforme as pesquisas realizadas pela Fundação João Pinheiro (2013) e o Observatório das Metrópoles (2009). Calculou-se o déficit habitacional e a inadequação de domicílios de 5.561 municípios, conforme descrito anteriormente. Manaus está entre os cinco municípios brasileiros com maior déficit habitacional absoluto, com total de 105.587 mil unidades habitacionais, apenas atrás de São Paulo, Rio de Janeiro, Brasília e Salvador. Isso representa 22,9\% do déficit total relativo, ou seja, o maior déficit relativo do país (FUNDAÇÃO JOÃO PINHEIRO, 2013). Segundo os estudos do Observatório das Metrópoles (2009), Manaus apresenta os seguintes dados:

- 225.784 domicílios permanentes apresentam algum tipo de carência de infraestrutura, portanto são considerados inadequados para moradia;

- 104.371 domicílios apresentam serviço inadequado de abastecimento de água; 
- 167.311 domicílios apresentam problemas de esgotamento sanitário;

- 7.602 apresentam problemas para descartar seu lixo, pois inexiste coleta.

De acordo com o IBGE (2010), Manaus teve um crescimento populacional expressivo entre o período de 1991 a 2000. A população da cidade foi de 1 milhão de habitantes para 1,5 milhão. Tal crescimento populacional gerou diversas questões sociais, principalmente, na área da habitação.

Às inúmeras famílias, que não conseguiram ou não conseguem ter acesso à moradia digna, lhes restaram os espaços de florestas no entorno da cidade ou às margens dos igarapés, que foram gradativamente ocupados. Segundo Oliveira e Costa (2007), esses assentamentos precários em Manaus se formaram sem planejamento e muito rapidamente. Apenas depois de um longo período receberam infraestrutura necessária, fato que só aconteceu mediante muitas reivindicações dos moradores.

Esse processo continuou acontecendo por anos e, em 2002, por exemplo, consolidou-se em Manaus mais de 40 novos assentamentos precários que posteriormente se transformaram em bairros com infraestrutura precária. Alguns bairros que surgiram de assentamentos precários em Manaus foram os seguintes: Colônia Santo Antônio, Coroado, Compensa, Lírio do Vale, Mauazinho, Novo Israel, Santo Agostinho, Vila da Prata, Zumbi dos Palmares e parte do Tarumã (OLIVEIRA; COSTA, 2007). Alguns desses bairros são mais próximos do centro, possuem infraestrutura regular, aparelhos comunitários e são compostos por moradores de todas as classes sociais, enquanto outros, como Colônia Terra Nova, Monte das Oliveiras e Santa Etelvina, têm uma realidade bem diferente. Desse modo, os assentamentos e ocupações nas margens dos igarapés em Manaus surgiram como estratégias que as famílias pobres encontraram para ter acesso à moradia.

Em relação ao risco ambiental, as condições inadequadas de saneamento são consideradas de risco, quando comparado à proporção de domicílios nestas condições. Dentre as 39 áreas da cidade que foram estudadas pelo Observatório, nenhuma foi classificada como baixíssimo risco ou baixo risco ambiental, fato único entre todas as regiões metropolitanas estudadas. Apenas quatro áreas foram consideradas como de médio baixo risco ambiental: Japiim, Chapada, São Geraldo e Dom Pedro I. Outras 23 áreas foram classificadas nos dois grupos de maior risco ambiental, ou seja, são áreas onde mais de $60 \%$ dos domicílios apresentam inadequação em termos das condições de saneamento. As piores situações são encontradas na Área de Expansão da Zona Rural, Jorge Teixeira, Colônia Terra Nova, Tarumã, Ponta Negra, Santa Etelvina, Monte das Oliveiras e Cidade Nova (OBSERVATÓRIO DAS METRÓPOLES, 2009). 
Em função da rápida ocupação desordenada em Manaus, há um grande número de famílias residindo em áreas inadequadas, como as margens dos igarapés e os barrancos. Segundo os dados de ocorrência do Sistema da Defesa Civil (2014), a Zona Leste da cidade apresenta o maior número de famílias residindo em área de risco e com intenso adensamento populacional (média de $6.870 \mathrm{hab} . \mathrm{km}^{2}$ ), além de frequentes ocorrências de fenômenos de movimentos de massa e inundações. As áreas territoriais são classificadas de acordo com os graus de risco: baixo (R1), médio (R2), alto (R3) e muito alto (R4). E somente no bairro Colônia Antônio Aleixo, foram identificadas 4.778 edificações em área de risco classificadas nos níveis R3 e R4. No mesmo local no período janeiro a julho de 2014, foram registrados sete alagações, seis desabamentos e quatro deslizamentos.

Fica evidente nos dados da Defesa Civil a ausência de condições mínimas de infraestrutura de saneamento básico por toda a cidade. Segundo o Observatório das Metrópoles (2009), quase todas as áreas de Manaus estão sujeitas a riscos ambientais decorrentes da falta de infraestrutura e de saneamento. Esse fato coloca a cidade em pior situação quanto à condição socioambiental, quando comparado a todas as outras metrópoles do país. Em suma, a capital amazonense enfrenta sérios problemas ligados às questões da habitação, que vão desde a falta de moradia para todos até os riscos decorrentes da localização das casas e da ineficiência do poder público para saná-los.

\section{CONCLUSÃO}

A HIS surgiu no Brasil como uma medida de intervenção do governo para sanar a questão social habitacional brasileira, tendo em vista ser deficiente a produção de habitações alcançáveis aos setores de baixa renda. Isso levou os vários governos a adotarem medidas e criarem políticas com o objetivo de resolver o problema habitacional. Nos anos $2000 \mathrm{em}$ diante, diante dos déficits revelados pelas pesquisas e as inúmeras reivindicações dos movimentos populares, o governo Lula criou o PMCMV na tentativa de amenizar essa questão social. O governo Dilma, em sua campanha eleitoral, sinalizou mais de um milhão de moradias construídas para famílias de baixa renda através do PMCMV, no entanto, em uma rápida pesquisa constatou-se a construção de menos de 700.000 unidades. As mesmas promessas foram mantidas pelo governo Temer, mas também ainda se está longe de resolver a questão da habitação no Brasil.

Como vimos, tal movimento não foi decorrente apenas da boa vontade política, mas resultante da forte pressão de movimentos populares, que evidenciavam a insatisfação com a atuação do Estado na problemática, a qual afeta, 
sobretudo, as classes populares. Apesar da luta dos movimentos populares por habitação e ações governamentais, não se conseguiu sanar o déficit habitacional brasileiro através dos programas sociais. As estatísticas da fundação João Pinheiro demonstram evidências por todo país do quanto ainda se faz necessário investir na produção de habitações para as populações desfavorecidas. Entretanto, essas estatísticas não revelam a quantidade de assentamentos precários existentes no país, conforme a definição dada pelo Ministério das Cidades. Isto nos leva a questionar os dados oficiais e a examinar com maior profundidade o verdadeiro déficit habitacional do país, assim como a efetividade dos programas criados para favorecer a aquisição de moradias pela população de baixa renda.

No caso do Amazonas, a consolidação da ZFM trouxe perspectivas de melhoria de vida para o homem do interior e também para pessoas de outros estados do Norte que não desenvolveram uma economia de grande porte. Por isso, é comum ver em portos e rodoviárias da capital o desembarque diário de um grande número de pessoas advindas de outras regiões que chegam à capital amazonense em busca de melhores oportunidades. No entanto, o crescimento desordenado de Manaus e a falta de investimentos do poder público local resultaram na ocupação de bairros sem infraestrutura adequada e em zonas de risco. Assim, o problema não está só na falta da moradia digna, mas na falta de infraestrutura básica por toda a cidade, o que deixa a mesma no ranking das cidades que traduzem os maiores e piores números na área habitacional segundo Observatório das Metrópoles.

Os programas longe de solucionar o problema habitacional da cidade, ainda recebem inúmeras críticas das famílias beneficiarias. Por exemplo, o programa PROSAMIM, que apesar de ter melhorado o aspecto físico das margens dos igarapés próximos ao centro da cidade, para os moradores os apartamentos construídos são considerados pequenos, uma vez que as famílias em sua maioria são bastante numerosas. Em relação aos residenciais do "Viver Melhor", é comum ver nos noticiários locais denúncias referentes a problemas na obra dos apartamentos, à falta de segurança, transporte e serviços públicos próximos aos residenciais. Além do fato de todos os residenciais terem sido construídos em áreas de expansão distantes do centro da cidade. Desse modo, fica evidente que na fase de planejamento dos programas, os gestores e trabalhadores sociais não consideram o modo de vida das famílias e suas opiniões (FELIPPE, 2010).

Diante do exposto, conclui-se que Manaus, apesar de concentrar um dos polos industriais mais importantes do país e que gera bilhões de dólares, revela uma realidade complexa e contraditória com precários serviços de infraestrutura urbana, crescente ocupação em áreas de risco e intensas desigualdades espaciais. 


\section{REFERÊNCIAS}

AZEVEDO, S. Desafios da habitação popular no Brasil: políticas recentes e tendências. In: CARDOSO, L. A. (Org.) Habitação social nas metrópoles brasileiras: uma avaliação das políticas habitacionais em Belém, Belo Horizonte, Porto Alegre, Recife, Rio de Janeiro e São Paulo no final do século XX. Porto Alegre: ANTAC, 2007. p. 13-41 (Coleção Habitare)

BRASIL. Ministério das Cidades. Guia para o mapeamento e caracterização de assentamentos precários. Brasília, 2010. 82p.

. Ministério das Cidades. O Estatuto da Cidade comentado. São Paulo: MC; Aliança das Cidades, 2010. 120p.

Ministério das Cidades. Política Nacional de Habitação. Brasília: 2004. (Cadernos MCidades, n. 4, 104p)

BONDUKI, N. G. Origens da habitação social no Brasil. Análise Social, v. 24, n. 127 , p. $711-732,1994$.

CABRAL, M. Habitação e questão social: análise do caso brasileiro. Scripta Nova. Revista electrónica de Geografía y Ciencias Sociales, Barcelona, v. 09, n. 194, p. 1-26, 2005.

DEFESA CIVIL DO AMAZONAS. Relatório sobre as áreas de risco da Colônia Antônio Aleixo. Manaus: DCA, 2014.

FELIPPE, Maíra Longhinotti. Casa: uma poética da terceira pele. Psicologia $\&$ Sociedade, v. 22, n. 2, p. 299-308, 2010.

FERNANDES, N. N.; OLIVEIRA, A. C. T. Marechal Hermes e as (des) conhecidas origens da habitação social no Brasil: o paradoxo da vitrine nãovista. Scripta Nova. Revista Electrónica de Geografía y Ciencias Sociales, Barcelona, v. 14, n. 331, p. 1-17, 2010.

FUNDAÇÃO JOÃO PINHEIRO. Centro de Estatística e Informações. Déficit habitacional municipal no Brasil. Belo Horizonte: Centro de Estatísticas e Informações, 2013. 78p.

IANNI, O. Ditadura e agricultura: o desenvolvimento do capitalismo na Amazônia (1964-1978). 2. ed. Rio de Janeiro: Civilização Brasileira,1986.

IBGE - Instituto Brasileiro de Geografia e Estatística. SIS - Síntese de Indicadores Sociais. Brasília: IBGE, 2010. 
LARCHER, J. V. M. Diretrizes visando a melhoria de projetos e soluções construtivas na expansão de habitações de interesse social. 2005, 41f. Tese (Doutorado) - Universidade Federal do Paraná, Curitiba, 2005.

MARICATO, E. O estatuto da cidade periférica. In: CARVALHO, C. S.; ROSSBACH, A. (Orgs.). O Estatuto das cidades comentado. São Paulo: Ministério das cidades; Aliança das cidades, 2010. p.05-22.

Metrópole na periferia do capitalismo. São Paulo: Hucitec, 1996.

MOT'TA, L. D. A questão da habitação no Brasil: políticas públicas, conflitos urbanos e o direito à cidade. 2010. Disponível em: < http:/ conflitosambientaismg. lcc.ufmg.br/wp-content/uploads/2014/04/TAMC-MOTTA_Luana_-_A_ questao_da_habitacao_no_Brasil.pdf.>. Acesso em: 25 set. 2014.

OBSERVATÓRIO DAS METRÓPOLES. Vulnerabilidade socioambiental das regiões metropolitanas brasileiras. Rio de Janeiro: UFRJ, 2009.

OLIVEIRA, J. A.; COSTA, D. P. Conjuntos habitacionais e a expansão urbana de Manaus: Filigramas do processo de construção urbana e o papel das políticas habitacionais. Revista de Geografia da UFC, v. 06, n. 11, p. 1-13, 2007.

RANCIARO, M. M. M. A. Andirá: memórias do cotidiano e representações sociais. Manaus: EDUA, 2004.

SILVA, M. O. S. Política habitacional brasileira: frente e verso. São Paulo: Cortez, 1989.

VALLADARES, L. P. (Org.). Habitação em questão. 2. ed. Rio de Janeiro: Zahar, 1981. 196p. 